\title{
Stream order-dependent ecological impacts of agricultural and urban land use across ecoregions
}

\author{
Olaf Büttner ${ }^{1}$, James Jawitz ${ }^{2}$, and Dietrich Borchardt ${ }^{1}$ \\ ${ }^{1}$ Helmholtz-Centre for Environmental Research - UFZ \\ ${ }^{2}$ University of Florida
}

May 12, 2020

\begin{abstract}
Why have ecological targets for the majority of water bodies in Europe not been met despite decades of water protection programs? We hypothesize that restoration strategies have not adequately accounted for whole-river network perspectives, including interactions between stream orders, spatial patterns of pollutant sources, and ecoregion-dependent susceptibility. We used high-resolution data from Germany to identify relationships between urban wastewater-river discharge fraction (UDF), agricultural land use fraction (ALF), and ecological status by stream order across three ecoregions. We found ecological status of good or better in less than $8 \%$ of all river sections with the highest proportions in low-order streams and complete disappearance at higher orders. Increasing ALF impaired the ecological status for river reaches across all stream orders. In contrast, relationships between UDF and ecological status impairment were significant only in low-order streams, independent from ecoregion. Concentrating integrative restoration efforts in low-order streams would maximize the potential to mitigate anthropogenic impacts.
\end{abstract}

\section{Introduction}

The hydroecological conditions in populated river basins are affected by urban and agricultural land uses in complex ways, often resulting in hydro-morphological alterations, poor water quality, and deteriorated ecological status throughout entire river networks (1). Although correlations between land use and aquatic ecosystem health are generally known (2), there is still a poor understanding of the fundamental relationships between ecological water status and land use changes in terms of cause-effect linkages, their spatial dimensions, and the differentiation of overlying effects (3), even in the most densely monitored regions of the world, such as the EU $(4,5)$ and the US (6). However, the new generation of high-resolution data sets from multiple-scale environmental monitoring (5) provides new opportunities for synthesis, including disentangling the effects of multiple pressures and impacts on aquatic ecosystems (7-9).

Perhaps the globally most dense and most comprehensive environmental data set regarding river networks has been collected over the last two decades across Europe under the regime of the EU-Water Framework Directive (EU-WFD) (4). The ecological status is an assessment procedure based on biological indicators that compares the composition of communities at given sampling sites with reference conditions of low or undisturbed type-specific ecosystems $(10,11)$. Ecological status is determined for rivers, lakes, transitional waters, and coastal waters based on biological quality elements at multiple trophic levels (algae, macrophytes, benthic invertebrates, fish) and supported by physico-chemical and hydromorphological characteristics. The ecological status for surface water bodies (SWBs) is categorized in the EU-WFD regime as high, good, moderate, poor , orbad applying a 'one out, all out' principle, by the biological quality element which has received the worst rating (12). 
The most recent assessment by the European Environment Agency \{MathWorks, 2019 \#17\}shows at European scale only around $40 \%$ of SWBs in high or good ecological status (13). However, the spatial distribution of ecological status and pressures is not equally distributed, neither over Europe nor across nested catchments $(5,11)$. For example, the northern Scandinavian region and Scotland, as well as Estonia, Romania, Slovakia and several river basins in the Mediterranean region have a high proportion of water bodies in high orgood ecological status. In contrast, many of the central European regions have the highest proportion of water bodies that are inpoor or even bad ecological status (13). For example, only $8 \%$ of SWBs in Germany have good or better ecological status.

This situation is surprising because Germany has the highest wastewater processing rate in Europe (14), with more than $96 \%$ of wastewater from private households or public facilities routed to sewage treatment plants. Furthermore, in intensively-managed agricultural regions, which cover $55 \%$ of Germany's land surface, the Common Agricultural Policy (CAP) and supporting agro-environmental measures (15) have been implemented in Germany for more than two decades (16). However, so far these measures have failed to negate adverse ecological impacts $(5,17)$. In particular, comparison of the first (2010) and second (2016) River Basin Management Plan following the EU-WFD implementation in 2000 revealed that the ecological status of surface waters in Germany has not improved in almost two decades (13). Here, we focus on narrow down our research questions to rivers, which constitute $92 \%$ of all SWBs in Germany (18).

What are the reasons for this striking discrepancy between large-scale point and diffuse source control efforts and the failure of streams and rivers to ecologically recover in response to these measures? Our hypothesis is that current river restoration strategies are not effective because they do not account for crucial characteristics of whole river networks, such as ecoregion-dependent susceptibility (8), spatial heterogeneity of both agricultural land use (19) and human populations (20), including the associated impacts of distributed wastewater treatment plants in river networks (21) and the corresponding carry-over effects (22), hydrological convolution of loadings from upstream to downstream (23), and how the temporal evolution of these processes may manifest as time lags of years to decades in receiving water responses (24). If specific relationships for these characteristics can be identified, management programs may be reconsidered to more explicitly account for a spatial prioritization of restoration measures.

In order to test this hypothesis, we evaluated the strength of relationships between ecological status in 6300 natural river water bodies (RWBs) in Germany and two primary pressures - wastewater treatment plants as point sources and agricultural land use as diffuse sources - in an explicit river network approach. We combined information delivered by EU-WFD regarding ecological status with highly resolved spatial information of pressures. The agricultural land use fraction (ALF) is used as proxy for pressures resulting from land cultivation and the intensity of agricultural practices, and the urban discharge fraction (UDF defined as wastewater-discharge-ratio) is used as proxy for pressures resulting from urban land use. This information was combined based on the river network organization to account for hierarchical structures and connectivity of river segments. The river network structure is described by the Strahler order $(\omega)(25)$. We assessed relationships between pressures and ecological status with classifications based on stream order and also major ecoregions in Germany (Alps, elevation $>800 \mathrm{~m}$, Central highlands, $200 \mathrm{~m}<$ elevation $<800 \mathrm{~m}$, and central plains, elevation $<200 \mathrm{~m}$ ). These ecoregions can be interpreted as a slope and run-off gradient extending from south (Alps) to north (central plains).

With the combined data set of proxies for agricultural (ALF) and urban pressures (UDF), and ecological status differentiated for ecoregions, we examined three research questions: 1) How do urban pressures impact ecological status within and between lower- and higher-order streams? 2) What is the corresponding relationship for agricultural pressures? 3) Are urban and agricultural pressures regulated by different hydro-ecological susceptibility among ecoregions? 


\section{Results}

River network hierarchical structure and ecological status

\section{FIGURE 1}

Less than $8 \%$ of the $137.000 \mathrm{~km}$ total length of German rivers is classified with ecological status better than moderate (Fig. 1A). The dominant status classes are moderate (41\%) and poor (36\%), followed by bad (15\%). Lower-order streams $(\omega[?] 3)$ have the largest proportion of segments $(7.5 \%)$ with good or better ecological status (Fig. 1B) with a total length of $6026 \mathrm{~km}$. The fraction of lower-order streams ( $\omega[?] 3)$ with ecological status high orgood is 8 times larger than for higher-order streams. All ranges of ecological status from high to bad can be found in lower order streams ( $\omega[?] 3)$ whereas no segment in larger streams $(\omega>3)$ have a high ecological status (Fig. 1C). Based on median values (Fig. 1C), streams in orders $\omega=1$ and $\omega=2$ have a slightly better ecological status (moderate) than higher order streams (at the boundary between moderate and poor ).

Agricultural land use, urban wastewater, and ecological status across stream orders

FIGURE 2 (8 panels)

Complex and diverse relationships between ecological status, agricultural land use fraction (ALF), and urban discharge fraction (UDF) are evident across stream orders and ecoregions (Fig. 2A through E). For the pooled data across Germany (Fig. 2A), there is a significant relationship between the median ecological status and agricultural land use fraction $(\mathrm{p}<0.05$, Table 1$)$ that is well described with a quadratic function for lower-order streams $\left(\mathrm{R}^{2}=0.96, \mathrm{p}<0.05\right)$ and with a linear function for higher orders $\left(\mathrm{R}^{2}=0.97, \mathrm{P}\right.$ $<0.05)$. In contrast, a significant urban wastewater impacts could only be detected in low stream orders $(\omega[?] 3)$, which virtually disappeared in higher orders (Fig. 2E). In lower-order streams, the ecological status decreased linearly with increasing UDF (Table SI 1). In higher-order streams, there were no statistically significant differences between the 5 groups (UDF for $\omega>3$, Fig. 2E) such that for these streams, the ecological status is independent from UDF. The median UDF does not exceed $4 \%$ for lower order streams and is less than $0.5 \%$ for higher order streams (Fig. 2E and Table SI 3). Furthermore, looking at ALF, there is a statistically significant difference between high and goodversus moderate, poor, and bad data clusters. The median ALF ranges from $12 \%$ to $71 \%$ for lower-order streams, and from $47 \%$ to $58 \%$ for higher-order streams (Fig. 2A and SI Table 3). Based on median values, the ecological status for lower-order streams is good or better when median ALF $<32 \%$, and is worse than good for higher-order streams when median $\mathrm{ALF}>53 \%$ (Fig. 2A).

Agricultural land use, urban wastewater, and ecological status across ecoregions

FIGURE 3(6 panels)

In the Alps, a very clear pattern was detected (Fig. 2B) where ecological status of good or better was observed only for ALF $<29 \%$ and $<36 \%$ in lower- and higher-order streams, respectively. In the Central plains the median ALF for lower- and higher-order streams was higher than in the Central highlands and Alps (Fig. 2 B, C, D) with extensive forests and less agriculture in the highlands compared to the lowland plains. For the Central plains the median ALF is $>60 \%$ in both lower and higher stream orders (Table SI 3). In the Central highlands (Fig. 2 C) ecological status was not significantly different in higher-order streams, but declined in lower-order streams with increasing median ALF except for highecological status.

For each ecoregion, example RWBs with good or better ecological status as well as corresponding cases with a status worse thanmoderate are presented in Fig. 3. These maps show the river reach, land cover, and, where present, the location of WWTPs in the catchment. In each of the example catchments with ecological statusgood or better, ALF was very small $(<10 \%)$ (Fig. 3A, C and E). On the opposite side of the distribution, contrasting examples with high ALF $(>90 \%)$ consistently showed a badecological status in all three ecoregions (Fig. $3 \mathrm{~B}, \mathrm{D}$ and F) 
The relationships between UDF and ecological status in all three ecoregion are very similar. In lower-order streams the ecological status consistently declined with increasing median UDF (Fig. 2 F, G and H). In higher-order streams, the median UDF is generally lower and the ecological status appears to be independent from UDF.

The $75 \%$ percentile of UDF for lower-order streams was larger in the central plains (Fig. 2H) compared to Alps and central highlands. The largest median values for UDF per ecological status group were found in the Central plains (Fig. 2H).

\section{Discussion}

Proxies for urban and agricultural pressures

The anthropogenic pressures from agricultural land use and urban settlements have been identified as significant stressors on the ecological status of watercourses (26). Agricultural land use is a proxy for various changes in habitat conditions in watercourses, in particular through runoff regulation, watercourse straightening, loss of bank and floodplain vegetation, increased nutrient inputs from fertilization, increased soil erosion, and pesticide inputs (27). Urban settlements are characterised by far-reaching changes in the water environment due to paving of land surfaces, alteration of flow paths and water balances, watercourse straightening, stormwater runoff, and discharges of municipal or industrial wastewater (27). Because of the inherent complexities in the differential mapping of all resulting impact factors, relationships, and hierarchies, robust proxies are needed.

Median relationships between urban and agricultural pressures and ecological status across stream orders

According to our results, urban wastewater discharge impacts on ecological status are significant only for lower-order streams (Fig. 2 E). This is consistent with higher relative flow contributions from WWTPs in low-order streams because of low local dilution (28), with high dilution from upstream tributary flow convolution in higher stream orders. This pattern is consistent for the aggregated total data set (Fig. 2 E) and the subsets differentiated by ecoregions (Fig. $2 \mathrm{~F}, \mathrm{G}, \mathrm{H}$ ).

The median UDF thresholds for good ecological status differ significantly between the ecological regions studied (Alps $0.4 \%$, central highland ranges $0.9 \%$ and central plains 3.2\%; see Table SI 3). Alpine water bodies and their biota react most sensitively to wastewater discharges, in part because steep gradients induce comparatively short water residence times in hillslopes. Lowland waters in the central plains and their biota appear comparatively more robust and tolerate much higher wastewater percentages in a goodecological status. This higher resilience is presumably based on the higher buffering capacities of lowland waters, supported by naturally higher nutrient levels, higher temperature means and variances, and longer residence times with correspondingly stronger self-purification capacities. These relationships need further testing based on the general findings of this study.

The UDF interquartile ranges increase with declining ecological status (Fig. $2 \mathrm{E}, \mathrm{F}, \mathrm{G}, \mathrm{H}$ ) for all river orders $\omega$ [?] 3. Thus, increasing loads of wastewater are associated with more variable ecological responses of the water bodies such that other co-variables become increasingly important. It is noteworthy that in the central plains, water bodies with a high percentage of wastewater (UDF $75^{\text {th }}$ percentile $=12 \%$; Fig. $2 \mathrm{H}$ ) can still sustain a good ecological status. This corresponds to a threshold value that is 10 times higher than that of waters in low mountain ranges and the Alps.

In contrast to UDF, increasing ALF impairs the ecological status for river reaches across all stream orders. With regards to median trends for all small streams ( $\omega$ [?] 3) in Germany, an ecological status not better than moderate can be expected if ALF exceeds one third of the catchment area. If ALF exceeds $56 \%$ of land cover, then ecological status of no better than moderate can be expected for all stream orders in all ecoregions examined (Fig. 2A, SI Table 3). 
However, there are considerable differences between the ecoregions. In fact, the median ALF surrounding water bodies with goodecological status is lowest in Alpine regions ( $29 \%$ for $\omega$ [?] 3; $36 \%$ for $\omega>3$ ), increases for the Central highlands ( $31 \%$ for $\omega$ [?] 3; $47 \%$ for $\omega>3$ ), and is highest in the Central plains ( $61 \%$ for $\omega$ [?] $3 ; 69 \%$ for $\omega>3$ ). The relative sensitivity of water bodies and their biota to stressors from agricultural land use is generally similar to that of wastewater-related impacts. The fundamental difference, however, is that this effect persists for the agricultural land-use fraction in the higher stream order sections $(\omega>3)$.

A systematic directed increase in interquartile ranges between ecological status classes is not discernible for any of the ALF groups and we hypothesize that different sets of co-variables control the dependence of ecological status on agricultural land use.

It is evident that good ecological status can be maintained for all water body classes even with very high percentages of agricultural land use (Alps: 55 - 65\%, Central highlands $45-62 \%$, and Central plains 82 $84 \%$; see Table SI 3). These values are much higher compared to studies without differentiation of river systems and ecoregions (29).

Variability around median trends and diversity of spatial settings

FIGURE 4 (12 panels)

While significant trends were found for median values, there is high variability in the relationships between ecological status, agricultural land use and urban impacts (Fig. 2). This is illustrated and discussed by selected extreme cases with counter-intuitive combinations of land use and ecological status at comparable spatial scales (Fig. 4, SI Table 4). There were catchments in all three ecoregions with water body ecological status of good or better but also with very high proportions of agricultural land use (ALF $>90 \%$, Fig. 4 A, B, C). In the examples described here, there are conspicuous features of the water bodies that support inferences about hydro-morphological status, the location of extensively used or natural areas, and the characteristics of neighbouring water bodies. The case study from the Alpine ecoregion is a water body whose headwater is located in forested or semi-natural areas (Fig. $4 \mathrm{~A}$ ). The course of the water body is curved and meandering, which indicates a near-natural hydro-morphological status. In addition, there are numerous first order tributaries, some of which are located in natural areas such as wetlands. All these characteristics contribute to a corresponding resilience towards the otherwise dominant agricultural use. Similar conditions are shown by the case studies in the Central highlands (Fig. 4 B) and Central plains (Fig. 4 C). Both watercourses originate in forest areas or near-natural areas, show pronounced longitudinal profile developments, and, in the case of the Central Highlands, regularly follow near-natural areas in the immediate watercourse corridor.

By contrast, there were also catchments in all three ecoregions with water body ecological status of poor or bad but also with very low proportions of agricultural land use (ALF $<10 \%$, Fig. 4D, E, F). The example case in the Alpine ecoregion represents a network of 1st and 2nd order headwaters upstream of a larger settlement in a closed forest area (Fig. 4 D). In mountain regions, watercourses above settlement areas with steep gradients are sources of danger from flooding and bed load transport. In Germany and other mountainous regions in Europe, running waters in those settings are typically developed for flood protection, with heavily modified hydromorphology that constrains connectivity and habitat for biota. The poor ecological status in the absence of agricultural land-use in this example is most likely due to these changes. In each of the two other cases, high proportions of urban areas with discharges from sewage treatment plants are found in the water body itself and in the neighbouring subcatchment areas (Fig. 4 E), or the catchment area is completely urbanised (Fig. $4 \mathrm{~F}$ ). All water courses are comparatively elongated, which indicates a high degree of hydraulic engineering interventions, as a result of which the hydromorphological conditions and habitats have been degraded.

Similarly, we also found cases in all three ecoregions with goodor better ecological status but with high wastewater contents (UDF $>10 \%$ (Fig. $4 \mathrm{G}, \mathrm{H}, \mathrm{I}$ ). The case study from the alpine ecoregion is a water body into which an isolated settlement area discharges wastewater (Fig. $4 \mathrm{G}$ ). The course of the water body is highly curved and meandering, which indicates a near-natural hydro-morphological status, and the 
water corridor is forested over long stretches in the wastewater-polluted section of the river. The adjacent watercourse sections show similar spatial land use patterns and hydro-morphological characteristics. All these factors likely contribute to a corresponding resilience of the ecological status against the relatively high wastewater load. The land use configuration is even more pronounced in the case study for the Central Highlands (Fig. $4 \mathrm{H}$ ). Here, two wastewater treatment plants discharge wastewater, but the entire water corridor and the direct watercourse environment is formed by forest and near-natural areas. In addition, there is a first-order inflow from a sub-catchment area with neither agricultural nor urban land uses. The watercourse is curved and meandering, which indicates near-natural hydro-morphological conditions and potentially high habitat diversity. The case study from the lowland ecoregion (Fig. $4 \mathrm{I}$ ) is characterized by a single settlement area, but here, too, there are extensive areas above and below the wastewater discharge location that are either forested or near natural according to the land-use classification. The watercourse itself only touches the settlement area at the edge, is clearly curved and meandering, and is likely subject to little hydro-morphological changes with correspondingly high habitat diversity.

Finally, we also show cases for each of the three ecoregions in which the wastewater fraction is low (UDF $<1 \%$ ) and yet the ecological status is poor or bad (Fig. $4 \mathrm{~J}, \mathrm{~K}, \mathrm{~L}$ ). In each of these cases, the urban areas and the wastewater discharges are found in the headwaters, and agricultural land uses are predominant in the remainder of the catchment. The longitudinal courses of the water bodies are conspicuously elongated everywhere, indicating intense hydraulic engineering changes and likely degraded habitat conditions. In none of these case studies are there inflows from tributaries that are either slightly or not at all anthropogenically altered.

From the analysis of these extreme cases, it can be concluded that the spatial arrangement of anthropogenic stressors from agricultural land use and urban settlements in relation to natural system properties (minimally-impacted tributaries, connectivity, hydro-morphological settings) are important systematic factors that determine the extent of the ecological response to anthropogenic stressors.

Limitations of this study

Of course our study has inherent limitations with regard to the data basis and the derivation of proxies for the ecologically effective pressures from urban and agricultural land uses. Moreover, important determinants for ecological system properties of watercourses could not be mapped explicitly. This includes in particular the discharge regime with respect to magnitude, frequency, duration, and timing (30) or fragmentation (31). The correlation of ecological status versus UDF and ALF represent temporal averaging periods of one to six years (SI Table 2). The proxies for our study had to be derived from the routine monitoring carried out by environmental agencies, which is designed to record the state of the environment rather than to analyse causal relationships or understand the systemic relationships between environmental changes and ecological impacts. Inevitably, routine monitoring only covers a part of the essential variables. Alternative strategies have been proposed for the next generation of ecological monitoring systems (32). While each of these factors includes clear limitations for this study, the results indicate promising starting points for further work.

An important direction for future work is to differentiate the components from which ecological status is determined. This concerns the stressor-specific differentiation of the individual biotic indicators algae, macrophytes, macroinvertebrates and fish, the "one out-all out" principle versus alternative determinations, such as max-min, average or median indicator values. A complementary attempt may be made to further differentiate the proxies for the pressures resulting from agriculture and urban settlements.

Further research may follow our approach and expand across wider natural and anthropogenic impact gradients. A next step could be the extension of the analysis to other European countries aiming for a comparison of ecological status relationships with ALF between highly industrialized countries and less developed countries.

Environmental implications

With these limitations in mind we suggest a reconsideration of receiving water-oriented catchment manage- 
ment with regard to agricultural and urban pressures and impacts. Ecological protection measures can be more effectively allocated when targeting context-specific pressure and impact relations in a river network perspective. Starting in the early $20^{\text {th }}$ century, large scale urban drainage systems were implemented across Germany to tackle the worst water-related problems originating from urban emissions (33). However, our results show surprisingly clearly that the impact of urban emissions on the ecological status of small watercourses $(\omega[?] 3)$ is still severe. The pervasive and persistent effect of urban emissions on small streams is initially surprising because headwaters of river networks are predominantly located in rural, sparsely populated landscapes (Fang et al., 2018) where the amount of wastewater generated is correspondingly low. Ultimately, for this reason, low-tech wastewater treatment processes are more commonly used in rural areas and the permissible discharge limits according to the emission principle are less stringent than for large urban wastewater treatment plants (EU, 1992). The underlying pragmatic assumption has been that improved wastewater treatment is cost-effective to yield better receiving water quality, and that improvement of the ecological status can best be achieved by means of uniformly applied end-of-pipe measures in wastewater treatment and stormwater management. Against the background of our results, this may have been a costly misjudgment. And if investments continue to focus on larger wastewater treatment plants, as currently proposed to manage micropollutants (34), we will continue to miss the environmental targets for the vast majority of water bodies despite great expense.

Our approach and results help to address this problem, emphasizing the need to scale down efforts for protecting the ecological health of our receiving waters with regard to urban emissions, and the need to improve quantitative cause-effect relationships in the receiving water system for operational application. Highly developed societies today have reached a high efficiency with respect to physical-chemical purification of the large wastewater volumes in cities (35), however it is debatable whether we should extensively expand traditional treatment approaches to small streams. Suggested alternative approaches include more efficient source control $(36,37)$ combined with physico-chemical pollution abatement employing enhanced naturebased solutions (38), hydrologic management measures of stormwater runoff $(39,40)$, and morphologic restoration (41). Such integrated approaches would yield higher ecological quality throughout the receiving water network.

Policies for environmentally compatible agriculture and agronomic management also must be devised accordingly. To our surprise, we found good ecological status in water bodies where the predominant catchment land use is agricultural (median up to $60 \%$ in Central plains at stream orders $\omega[?] 3$, in extreme cases even at agricultural land-use fractions larger than $90 \%$ in all three ecoregions). This is an indication that the relationship between agricultural land use and ecological status of water bodies depends on not just the proportion of land use but also the type and intensity of agricultural activities, as well as the spatial location and configuration in the river network, and the presence of additional pressures from urban areas. It is therefore a question of water-sensitive agriculture, which limits its unavoidable influences (e.g. discharge regulation and drainage, morphological changes, loss of bank and floodplain vegetation, nutrient inputs, soil erosion, pesticide inputs) to a compatible level for aquatic ecosystems locally and at catchment levels. The type and intensity of agricultural land use needs to be differentiated according to its location in the catchment area and, in particular, consistently and comprehensively protect low-order watercourses ( $\omega[?] 3)$.

\section{Material and Methods}

Urban discharge fraction (UDF) as a proxy for point sources

The urban discharge fraction (UDF) was defined as a proxy for point source impacts as the percentage of water in the river that originates from WWTPs:

$$
\overline{U D F=\frac{Q U}{Q U+Q R} \quad(1)}
$$


where QU is wastewater treatment plant (WWTP) outflow, and QR is discharge of the river at the location of the WWTP effluent. QU was calculated as sum of wastewater from households and small industries (QH), storm water (QSW), and sewer infiltration water (QSIW):

$$
\overline{Q U=Q H+Q S W+Q S I W \quad(2)}
$$

where QH was estimated as PE multiplied by the mean water usage per capita in Germany (126L/day) (42). The sum of QSW and QSIW were obtained from the German statistical yearbook (42) and proportional to PE distributed to the WWTP. The QR was obtained by the mesoscale Hydrological Model (mHM) developed by (43). The Q10 low flow was used for UDF calculation (10\% of the time the measured discharge is lower than Q10), because this discharge is an established design criterion for the treatment requirements of wastewater discharges in Germany (44). This criterion was also recently used for US wide estimates on effects of water pollution by micropollutants (45). The stream order $\omega$ for each WWTP effluent location was derived from the EU Hydro river network (46). Finally, WWTPs were assigned to the RWBs of the EU-WFD (47)).

Agricultural land use fraction (ALF) as a proxy for non-point sources

ALF is defined as percentage of agricultural land use of an area that drains to a river segment. It can be interpreted as proxy of an integrated impact to a certain river segment originating from diffuse sources.

The specific area that drains to a stream segment is available within the EU Hydro data set $(46,48)$. Details about deriving the drainage areas per segment are given in (48) and SI. The land use within the drainage area of a segment was obtained from the CORINE Land Cover data set (CLC) (49), which distinguishes 5 classes of land use on the highest level: 1) artificial surfaces, 2) agricultural surfaces, 3) forests and semi-natural areas, 4) wetlands and 5) water bodies. For more details on CLC, see SI and (49). A description of the algorithm used to derive ALF is given in SI.

Assessment of ecological health of rivers

Ecological status is used within the WFD as a measure of the ecological health of rivers (13) (12). Ecological status is an assessment of the quality of the structure and functioning of surface water ecosystems and is available for almost all SWBs in Europe (47). Ecological status is categorical with possible values high , good ,moderate, poor, and bad.

\section{Ecoregions in Germany}

The three ecoregions were selected following the German LAWA (German states water association) organization: a) Alps and Alpine foothills, altitude $>800 \mathrm{~m}$, b) Central highlands, altitude ca. $200-800 \mathrm{~m}$ and higher, c) Central plains, altitude $<200 \mathrm{~m}(50,51)$. The ecoregions are as mandatory information included in the WFD data set (12).

Data sets used in the study

An overview of all used data and the list of sources is given in SI Table 2. All used data are available on public websites except the WWTP data for PE $<2000$ (referred to as small WWTP) and mHM discharge data. These small WWTP data underlie some confidentiality constraints from the local authorities, therefore these data cannot be made publicly available, but the authors are willing to work with those needing access to these data. The mHM result data can be requested from the authors.

Statistical methods used

Data were separated in two subsets based on smaller streams with $\omega$ [?] 3 and larger streams with $\omega>3$. The plots and statistics are related to these groups. Boxplots were used for characterization of distribution of ecological status in relation to UDF and ALF for both subsets (Fig. 2). We used the non-parametric Kruskal-Wallis test to assess if there are statistically significant differences between groups according to their ecological status (high, good ,moderate, poor, bad ). The test compares the medians of the five groups 
within both subsets to determine if the samples come from the same population. A multiple comparison procedure was used in a way that all pairs of groups are tested against each other with the Bonferroni method (52). The medians of the five groups within each subset were tested for a positive trend using the nonparametric Mann-Kendall and Sen's methods (53). The significance level alpha was set to 0.05 for all statistical tests.

Acknowledgments

We thank the authorities of 13 federal states in Germany for providing us data for WWTPs with PE $<2000$ to research projects with UFZ under a confidentiality agreement from the German states' authorities. Due to confidentiality constraints, these data cannot be made publicly available, but the authors are willing to work with those needing access to these data for scientific purposes.

This research was a part of the series of International Summer Workshops on "Complex Networks: Structure and Functions," held during 2015-2018 in Seoul, South Korea; Dresden, Germany; West Lafayette, IN; Gainesville, FL; and Ft. Collins, CO. The authors extend their appreciation to all the colleagues who participated in this interdisciplinary, collaborative research effort. We are grateful to the organizations and logistical support by the institutions that hosted these Summer Workshops.

Competing interests: The authors declare that they have no competing interests.

\section{References and Notes}

1. C. J. Vörösmarty, P. B. McIntyre, M. O. Gessner, D. Dudgeon, A. Prusevich, P. Green, S. Glidden, S. E. Bunn, C. A. Sullivan, C. R. Liermann, Global threats to human water security and river biodiversity. Nature . 467 (7315):555 (2010).

2. J. D. Allan, Landscapes and Riverscapes: The Influence of Land Use on Stream Ecosystems. Annual Review of Ecology, Evolution, and Systematics . 35 (1):257-84 (2004).

3. L. Carvalho, E. B. Mackay, A. C. Cardoso, A. Baattrup-Pedersen, S. Birk, K. L. Blackstock, G. Borics, A. Borja, C. K. Feld, M. T. Ferreira, L. Globevnik, B. Grizzetti, S. Hendry, D. Hering, M. Kelly, S. Langaas, K. Meissner, Y. Panagopoulos, E. Penning, J. Rouillard, S. Sabater, U. Schmedtje, B. M. Spears, M. Venohr, W. van de Bund, A. L. Solheim, Protecting and restoring Europe's waters: An analysis of the future development needs of the Water Framework Directive. Science of The Total Environment . 658 :1228-38 (2019).

4. S. Richter, J. Völker, D. Borchardt, V. Mohaupt, The Water Framework Directive as an approach for Integrated Water Resources Management: results from the experiences in Germany on implementation, and future perspectives. Environmental earth sciences . 69 (2):719-28 (2013).

5. European Environment Agency, The European environment - state and outlook 2015: synthesis report. (Copenhagen, 2015)

6. E. Wohl, P. L. Angermeier, B. Bledsoe, G. M. Kondolf, L. MacDonnell, D. M. Merritt, M. A. Palmer, N. L. Poff, D. Tarboton, River restoration. Water Resources Research . 41 (10) (2005).

7. S. J. Ormerod, M. Dobson, A. G. Hildrew, C. R. Townsend, Multiple stressors in freshwater ecosystems. Freshwater Biology .55 (s1):1-4 (2010).

8. K. Tockner, M. Pusch, D. Borchardt, M. S. Lorang, Multiple stressors in coupled river-floodplain ecosystems. Freshwater Biology .55 (s1):135-51 (2010).

9. S. K. Bopp, R. Barouki, W. Brack, S. Dalla Costa, J.-L. C. M. Dorne, P. E. Drakvik, M. Faust, T. K. Karjalainen, S. Kephalopoulos, J. van Klaveren, M. Kolossa-Gehring, A. Kortenkamp, E. Lebret, T. Lettieri, S. Nørager, J. Rüegg, J. V. Tarazona, X. Trier, B. van de Water, J. van Gils, Å. Bergman, Current EU 
research activities on combined exposure to multiple chemicals. Environment International .120 :544-62 (2018).

10. S. Birk, W. Bonne, A. Borja, S. Brucet, A. Courrat, S. Poikane, A. Solimini, W. van de Bund, N. Zampoukas, D. Hering, Three hundred ways to assess Europe's surface waters: An almost complete overview of biological methods to implement the Water Framework Directive.Ecological Indicators . 18 :31-41 (2012).

11. M. Kuemmerlen, P. Reichert, R. Siber, N. Schuwirth, Ecological assessment of river networks: From reach to catchment scale.Science of The Total Environment . 650 :1613-27 (2019).

12. European Commission, COMMON IMPLEMENTATION STRATEGY FOR THE WATER FRAMEWORK DIRECTIVE AND THE FLOODS DIRECTIVE - WFD Reporting Guidance 2016. (Brussels, 2016)

13. European Environment Agency, European waters - Assessment of status and pressures 2018. (EEA Report 07/2018, Luxembourgh, 2018)

14. European Environment Agency, UWWTD database. (2017), (available at: https://www.eea.europa.eu/data-and-maps/data/waterbase-uwwtd-urban-waste-water-treatment-directive$5)$.

15. W. A. H. Rossing, P. Zander, E. Josien, J. C. J. Groot, B. C. Meyer, A. Knierim, Integrative modelling approaches for analysis of impact of multifunctional agriculture: A review for France, Germany and The Netherlands. Agriculture, Ecosystems 83 Environment .120 (1):41-57 (2007).

16. M. Volk, S. Liersch, G. Schmidt, Towards the implementation of the European Water Framework Directive?: Lessons learned from water quality simulations in an agricultural watershed. Land Use Policy .26 (3):580-8 (2009).

17. European Environment Agency, The EU Water Framework Directive - integrated river basin management for Europe. (2016), (available at: The EU Water Framework Directive - integrated river basin management for Europe).

18. Water Framework Directive The status of German waters 2015. (2016)

19. J. A. Priess, J. Hauck, R. Haines-Young, R. Alkemade, M. Mandryk, C. J. Veerkamp, G. Bela, P. Berry, R. Dunford, P. Harrison, H. Keune, M. Kok, L. Kopperoinen, T. Lazarova, J. Maes, G. Pataki, E. Preda, C. Schleyer, A. Vadineanu, G. Zulian, New EU-Level Scenarios on the Future of Ecosystem Services. In: M. S, A. B, S. K, R. S, C. B, editors. Atlas of Ecosystem Services. Cham: Springer International Publishing; 2019. p. $135-40$.

20. Y. Fang, S. Ceola, K. Paik, G. McGrath, P. S. C. Rao, A. Montanari, J. W. Jawitz, Globally Universal Fractal Pattern of Human Settlements in River Networks. Earth's Future . 6 (8):1134-45 (2018).

21. S. Yang, O. Büttner, J. Jawitz, W., R. Kumar, P. S. C. Rao, D. Borchardt, Spatial Organization of Population and Wastewater Treatment Plants in Urbanized River Basins. Water Resources Research . (2019).

22. C. G. Jäger, D. Borchardt, Longitudinal patterns and response lengths of algae in riverine ecosystems: A model analysis emphasising benthic-pelagic interactions. Journal of Theoretical Biology .442:66-78 (2018).

23. R. Dupas, B. W. Abbott, C. Minaudo, O. Fovet, Distribution of Landscape Units Within Catchments Influences Nutrient Export Dynamics.Frontiers in Environmental Science . 7 (43) (2019).

24. K. Van Meter, P. Van Cappellen, N. Basu, Legacy nitrogen may prevent achievement of water quality goals in the Gulf of Mexico.Science . 360 (6387):427-30 (2018).

25. A. N. Strahler, Quantitative analysis of watershed geomorphology.Eos, Transactions American Geophysical Union .38 (6):913-20 (1957).

26. S. E. Apitz, M. Elliott, M. Fountain, T. S. Galloway, European environmental management: Moving to an ecosystem approach.Integrated Environmental Assessment and Management .2 (1):80-5 (2006). 
27. D. Hering, L. Carvalho, C. Argillier, M. Beklioglu, A. Borja, A. C. Cardoso, H. Duel, T. Ferreira, L. Globevnik, J. Hanganu, S. Hellsten, E. Jeppesen, V. Kodeš, A. L. Solheim, T. Nõges, S. Ormerod, Y. Panagopoulos, S. Schmutz, M. Venohr, S. Birk, Managing aquatic ecosystems and water resources under multiple stress - An introduction to the MARS project. Science of The Total Environment .503-504:1021 (2015).

28. S. Yang, O. Büttner, R. Kumar, C. Jäger, J. W. Jawitz, P. S. C. Rao, D. Borchardt, Spatial patterns of water quality impairments from point source nutrient loads in Germany's largest national River Basin (Weser River). Science of The Total Environment . 697 :134145 (2019).

29. C. K. FELD, Response of three lotic assemblages to riparian and catchment-scale land use: implications for designing catchment monitoring programmes. Freshwater Biology . 58 (4):715-29 (2013).

30. M. Palmer, A. Ruhi, Linkages between flow regime, biota, and ecosystem processes: Implications for river restoration. Science $\mathbf{. 3 6 5}$ (2019).

31. G. Grill, B. Lehner, M. Thieme, B. Geenen, D. Tickner, F. Antonelli, S. Babu, P. Borrelli, L. Cheng, H. Crochetiere, H. Ehalt Macedo, R. Filgueiras, M. Goichot, J. Higgins, Z. Hogan, B. Lip, M. E. McClain, J. Meng, M. Mulligan, C. Nilsson, J. D. Olden, J. J. Opperman, P. Petry, C. Reidy Liermann, L. Sáenz, S. Salinas-Rodríguez, P. Schelle, R. J. P. Schmitt, J. Snider, F. Tan, K. Tockner, P. H. Valdujo, A. van Soesbergen, C. Zarfl, Mapping the world's free-flowing rivers.Nature . 569 (7755):215-21 (2019).

32. P. Haase, J. D. Tonkin, S. Stoll, B. Burkhard, M. Frenzel, I. R. Geijzendorffer, C. Häuser, S. Klotz, I. Kühn, W. H. McDowell, M. Mirtl, F. Müller, M. Musche, J. Penner, S. Zacharias, D. S. Schmeller, The next generation of site-based long-term ecological monitoring: Linking essential biodiversity variables and ecosystem integrity. Science of The Total Environment . 613-614 :1376-84 (2018).

33. D. Blackbourn, The conquest of nature: water, landscape, and the making of modern Germany (Random House; 2007).

34. R. I. L. Eggen, J. Hollender, A. Joss, M. Schärer, C. Stamm, Reducing the Discharge of Micropollutants in the Aquatic Environment: The Benefits of Upgrading Wastewater Treatment Plants.Environmental Science \& Technology . 48 (14):7683-9 (2014).

35. S. Arden, J. W. Jawitz, The evolution of urban water systems: societal needs, institutional complexities, and resource costs. Urban Water Journal . 16 (2):92-102 (2019).

36. T. A. Larsen, W. Gujer, Waste design and source control lead to flexibility in wastewater management. Water Science and Technology . 43 (5):309-18 (2001).

37. J. Lienert, T. Bürki, B. I. Escher, Reducing micropollutants with source control: substance flow analysis of 212 pharmaceuticals in faeces and urine. Water Science and Technology . 56 (5):87-96 (2007).

38. J. Nivala, J. Boog, T. Headley, T. Aubron, S. Wallace, H. Brix, S. Mothes, M. van Afferden, R. A. Müller, Side-by-side comparison of 15 pilot-scale conventional and intensified subsurface flow wetlands for treatment of domestic wastewater. Science of The Total Environment . 658 :1500-13 (2019).

39. D. Borchardt, F. Sperling, Urban stormwater discharges: Ecological effects on receiving waters and consequences for technical measures. Water Science and Technology . 36 (8):173-8 (1997).

40. D. Borchardt, B. Statzner, Ecological impact of urban stormwater runoff studied in experimental flumes: Population loss by drift and availability of refugial space. Aquatic Sciences .52 (4):299-314 (1990).

41. S. Muhar, K. Januschke, J. Kail, M. Poppe, S. Schmutz, D. Hering, A. D. Buijse, Evaluating goodpractice cases for river restoration across Europe: context, methodological framework, selected results and recommendations. Hydrobiologia . 769 (1):3-19 (2016).

42. Statistisches Bundesamt (Destatis), Statistisches Jahrbuch 2019. (Wiesbaden, DE, 2019) 
43. M. Zink, R. Kumar, M. Cuntz, L. Samaniego, A high-resolution dataset of water fluxes and states for Germany accounting for parametric uncertainty. Hydrol Earth Syst Sci . 21 (3):1769-90 (2017).

44. D. Borchardt, F. Sperling, Urban stormwater discharges: ecological effects on receiving waters and consequences for technical measures. Water Science and Technology . 36 (8-9):173-8 (1997).

45. J. Rice, P. Westerhoff, High levels of endocrine pollutants in US streams during low flow due to insufficient wastewater dilution.Nature Geoscience . 10 (8):587-91 (2017).

46. European Environment Agency, EU HYDRO - River Network Database. (2020), (available at: https://www.eea.europa.eu/data-and-maps/data/external/eu-hydro-2013-river-network.0).

47. European Environment Agency, WFD database (2018), (available at: https://www.eea.europa.eu/themes/water/european-waters/water-quality-and-water-assessment/waterassessments/delineation-of-water-bodies).

48. A pan-European river and catchment database. (Luxembourg, 2007)

49. European Environment Agency, Corine Land Cover (CLC) 2012, Version 18.5.1 Release date: 19-09-2016. (2018), (available at: https://land.copernicus.eu/pan-european/corine-land-cover/clc-2012).

50. Hydromorphologische Steckbriefe der deutschen Fließgewässertypen - Anhang 1 von ,,Strategien zur Optimierung von Fliessgewasser-Renaturierungsmassnahmen und ihrer Erfolgskontrolle“. (Dessau-Rosslau, 2014)

51. Gewasser in Deutschland - Zustand und Bewertung. (Dessau-Rosslau, 2017)

52. T. Pohlert, The pairwise multiple comparison of mean ranks package (PMCMR). R package . 27 (2019):9 (2014).

53. trend: Non-Parametric Trend Tests and Change-Point Detection. (2018), (available at: https://cran.rproject.org/web/packages/trend/vignettes/trend.pdf).

54. O. Buttner, DE-WWTP - data collection of wastewater treatment plants of Germany (status 2015, metadata). HYDROSHARE (2020).

Figures and Tables 

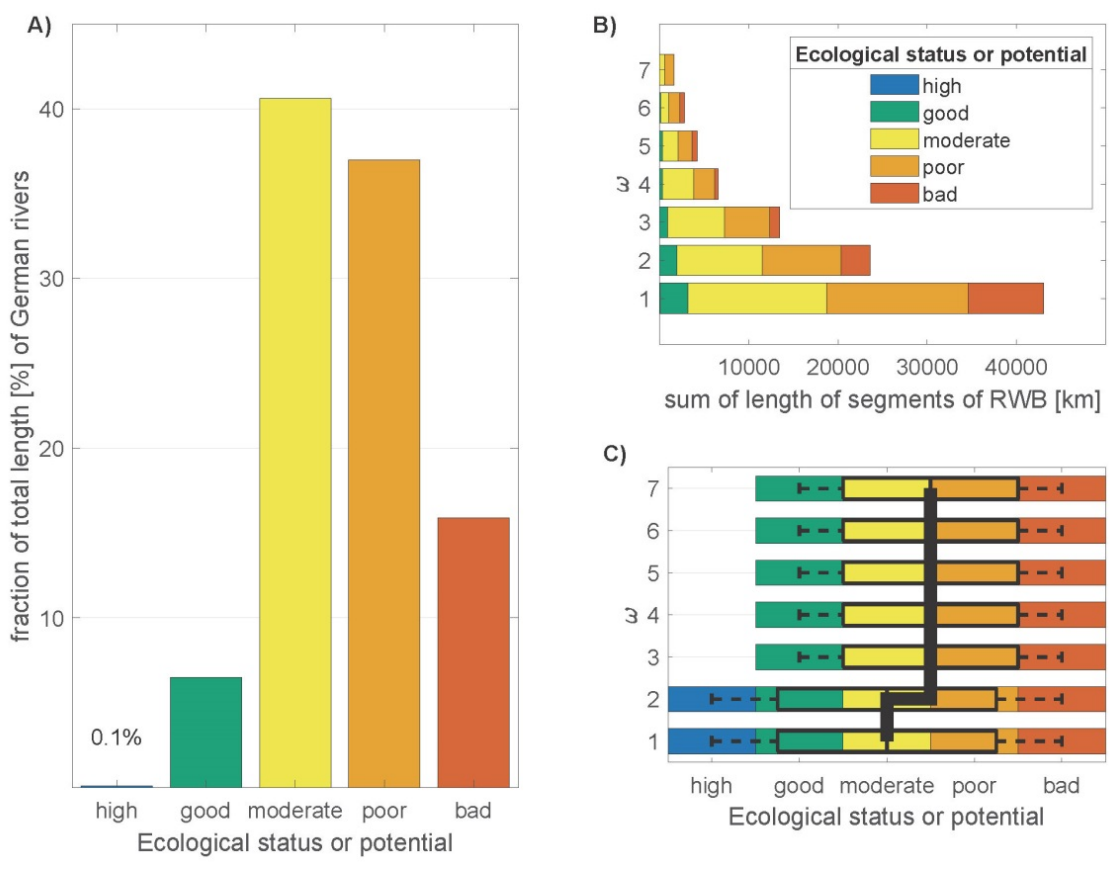

Fig. 1 Ecological status and spatial structure information for German rivers. (A) Fraction of river length grouped by Ecological status. (B) sum of length of segments of RWBs separated by stream order ( $\omega)$. (C) medians and box whisker plots of Ecological status for different stream orders $(\omega)$

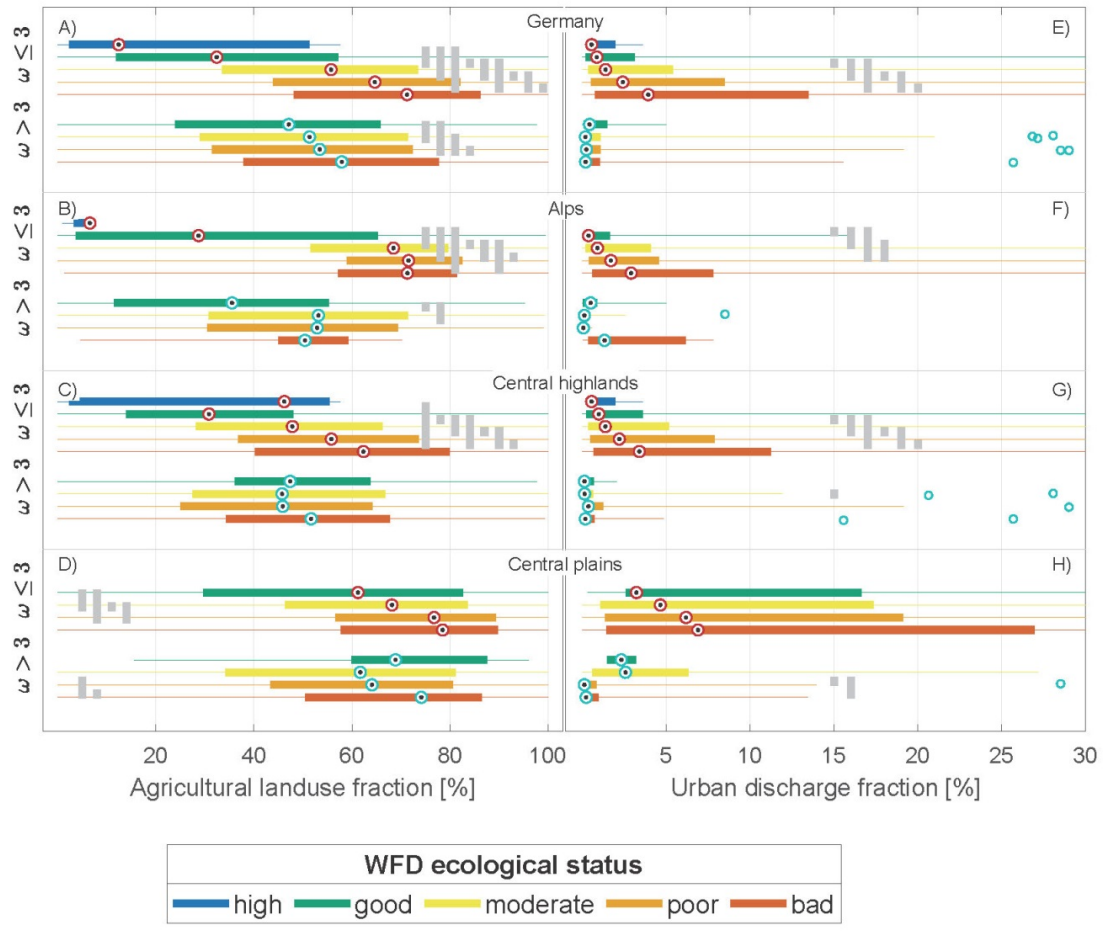


Fig. 2. Boxplots of ALF (left) and UDF (right) grouped by ecological status, $\omega$, and ecoregion. (A) ALF for all RWBs in Germany. (B) ALF for ecoregion Alps. (C) ALF for ecoregion Central highlands, (D) ALF for ecoregion Central plains. (E) UDF for all RWBs in Germany. (F) UDF for ecoregion Alps. (G) UDF for ecoregion Central highlands, (H) UDF for ecoregion Central plains. Dotted circles indicate median values. Vertical grey bars indicate significant differences between groups based on the non-parametric Kruskal-Wallis test. If there are no bars (e.g. $2 \mathrm{C}, \omega>3)$ ) there is no statistically significant difference between mean ranks of groups.

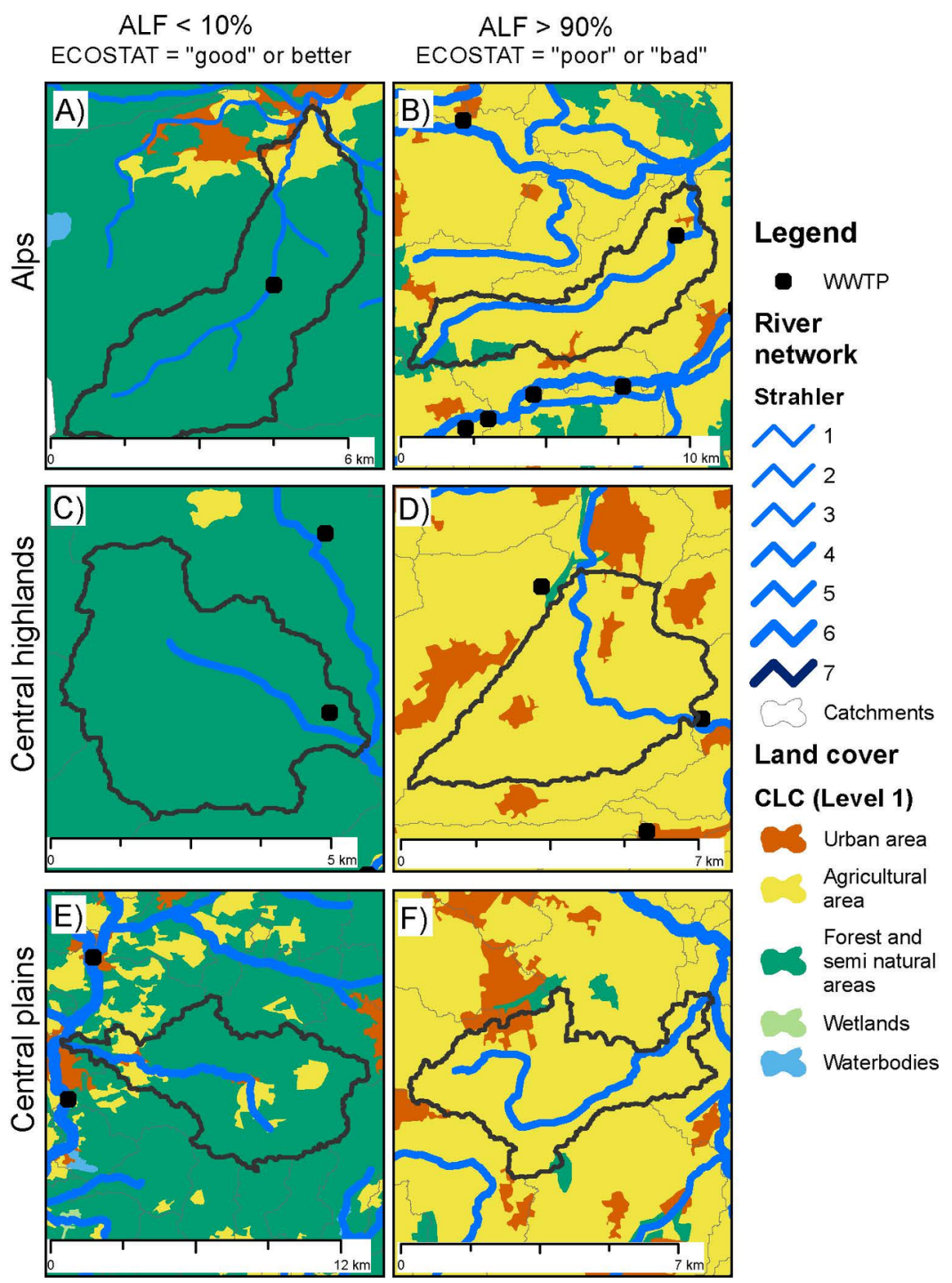

Fig. 3 Examples of land use in specific areas of segments in different ecoregions grouped by ecological status and ALF. (A) High or good ecological status and small ALF in the Alps. (B) Bad ecological status and high ALF in the Alps. (C) High or good ecological status and small ALF in the Central highlands. (D) Bad 
ecological status and high ALF in the Central highlands. (E) High or good ecological status and small ALF in the Central plains. (F) Bad ecological status and high ALF in the Central plains.
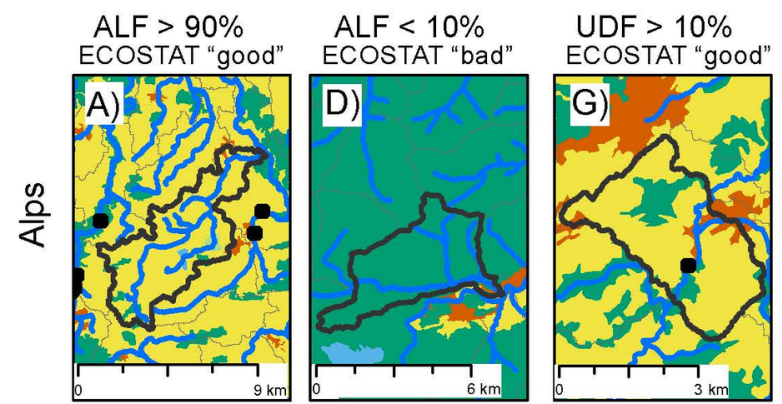

UDF $<1 \%$
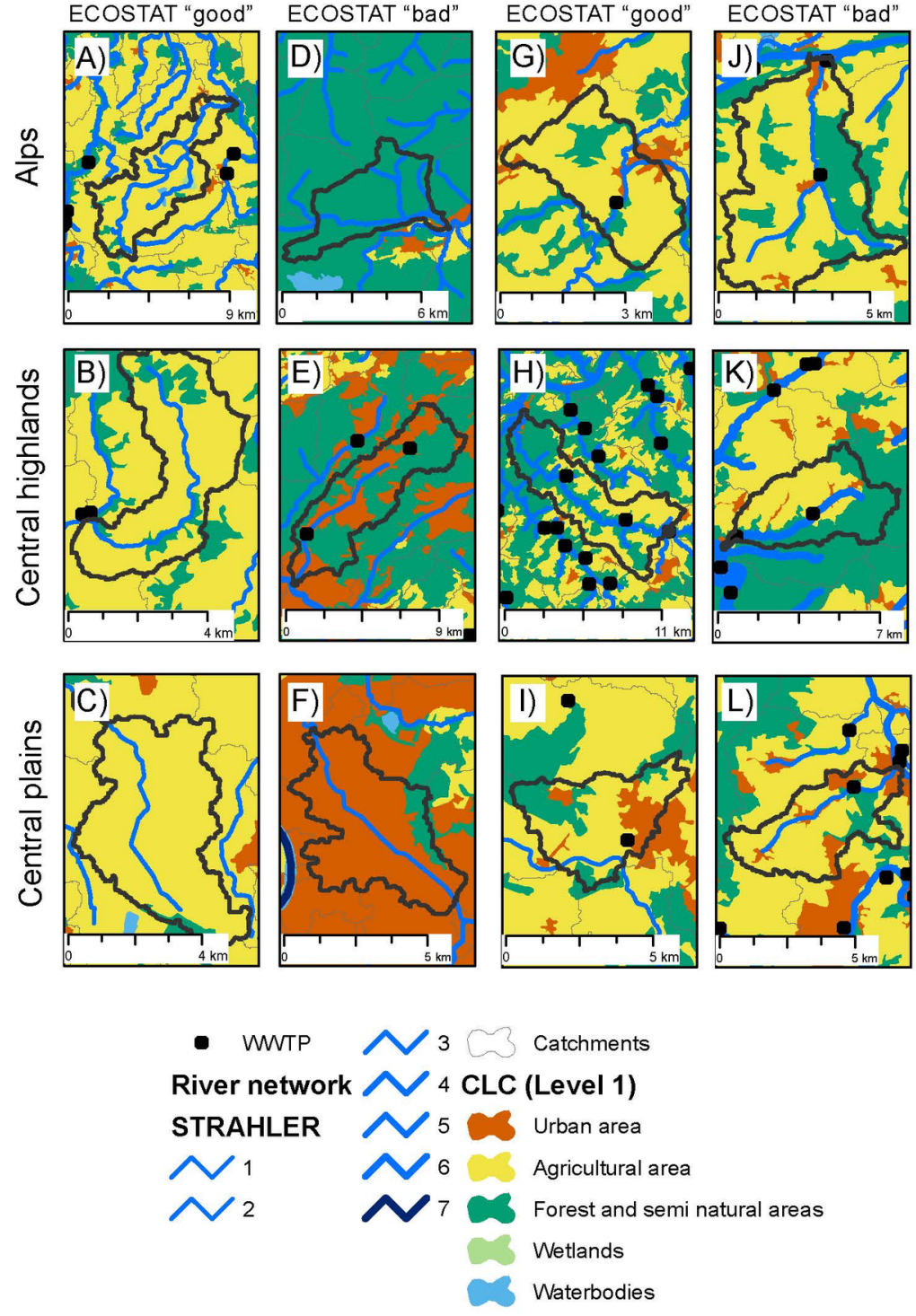

Fig. 4. Examples of land use in specific areas of segments in different ecoregions related to different point and diffuse pressure with counter-intuitive ecological status. The examples show the extreme cases that don't follow the median distribution of ecological status: High ALF and good ecological status (A-C); small ALF and bad ecological status (D-F); high UDF and good ecological status (G-I); small UDF and badecological status (J-L) 